\title{
Use of DNA microarray analysis in diagnosis of bacterial and fungal endophthalmitis
}

This article was published in the following Dove Press journal:

Clinical Ophthalmology

28 February 2012

Number of times this article has been viewed

Tsutomu Sakai'

Kenichi Kohzaki'

Akira Watanabe'

Hiroshi Tsuneoka'

Mitsunobu Shimadzu²

'Department of Ophthalmology, Jikei University School of Medicine, ${ }^{2}$ Mitsubishi Chemical Medience

Corporation, Tokyo, Japan
Correspondence: DrTsutomu Sakai Department of Ophthalmology, Jikei University School of Medicine, 3-25-8 Nishishinbashi, Minato-ku,

Tokyo 105-846I, Japan

Tel +8 I 33433 I I I | ext 358 I

$\mathrm{Fax}+81334331936$

Email tstmski@jikei.ac.jp
Background: To examine the utility of DNA microarray analysis for identifying causative microorganisms in endophthalmitis.

Methods: Thirteen samples of vitreous fluid (VF) were obtained from 13 patients during vitrectomy. Vitreous fluids from three patients with suspected endophthalmitis and ten controls without infection were subjected to testing for the presence of bacteria and fungi in culture tests, polymerase chain reaction (PCR) analysis, and DNA microarray analysis.

Results: No control sample was positive for bacteria or fungi in the culture test, PCR, or microarray analysis. Specimens from two patients (Cases 1 and 2) with suspected endophthalmitis were positive for bacteria in PCR, and a specimen from one patient (Case 3) was positive for fungi in PCR. Klebsiella pneumonia (Case 1), Streptococcus agalactiae (Case 2), and Candida parapsilosis (Case 3 ) in the PCR-positive specimens were identified by DNA microarray analysis within 24 hours. Culture results were also positive for $K$. pneumonia in Case 1, S. agalactiae in Case 2, and $C$. parapsilosis in Case 3, but required 3 to 4 days to obtain.

Conclusions: Microarray analysis is complementary to routine cultures for identifying causative microorganisms and is likely to be a useful tool in patients with suspected endophthalmitis who require rapid diagnosis and early antibiotic treatment.

Keywords: DNA microarray, endophthalmitis, microorganism, vitreous fluid

\section{Introduction}

Endophthalmitis is a devastating ocular disorder that leads to visual blindness. Rapid detection and identification of the causative pathogens is crucial for vision-saving diagnosis and treatment. Molecular techniques using multiplex or broad-range PCR enable rapid detection and identification of causative pathogens in ocular infectious diseases. ${ }^{1-3}$ Several problems remain to be solved, however. Multiplex PCR has the drawback of allowing only a limited number of genes to be analyzed in one reaction, and pre-identification of the species level is required. Analysis of amplicons by DNA sequencing, after broad-range PCR, are the most used techniques for identifying DNA, but the time and effort associated with data analysis lead to some limitations. Therefore, improved high-throughput genotyping methods that are sensitive and discriminative are needed.

DNA microarray technology is a promising genotyping method that allows simultaneous identification of a wide variety of genes ${ }^{4-8}$ and rapid determination of the genetic profile of a microorganism in a single experiment. ${ }^{6-8}$ Thus, this method may be useful for genetic screening and identification of microorganisms. The aim of this 
study was to examine the utility of DNA microarray analysis for identifying causative microorganisms in endophthalmitis.

\section{Materials and Methods Clinical sample collection}

Thirteen samples of vitreous fluid (VF) obtained from 13 patients during vitrectomy were prospectively analyzed at our university hospital. Informed consent was obtained from each patient after an explanation of the purpose and potential adverse effects of the procedure. This study was performed in accordance with the Helsinki Declaration of 1975 (1983 revision) and the institutional review boards of Jikei University. VF samples were collected from three subjects with clinically diagnosed endophthalmitis, and control VF samples were obtained from ten subjects undergoing vitrectomy for macular hole, epiretinal membrane, retinal detachment, and proliferative vitreoretinopathy. VF samples were obtained under sterile operating conditions by aspiration with a syringe connected to the suction port of the vitreous cutter at the beginning of the vitrectomy procedure. The samples were divided in half, with one portion used for conventional microbiological tests in the bacteriology laboratory of our university hospital and the other for PCR and microarray analysis in the Institute of Medical Technology.

\section{Bacterial isolation and conventional identification methods}

VF was stained using the Gram method for detection of bacteria and a $10 \%$ potassium hydroxide calcofluor white preparation for detection of fungi. Standard methods were followed for isolation and identification of bacteria and fungi.

\section{DNA purification and PCR amplification}

Genomic DNA was extracted from $50 \mu \mathrm{L}$ of VF according to the protocol of the QIAamp kit (Qiagen, Valencia, CA) and DNA was eluted in $50 \mu \mathrm{L}$ of QIAamp AE buffer. An aliquot of $2 \mu \mathrm{L}$ of the DNA template was used in each amplification reaction. The $16 \mathrm{~S}$ ribosomal ribonucleic acid gene (16S rDNA) was amplified from genomic DNA using a broad-spectrum PCR primer 5'-AGA GTT TGA TCC TGG CTC AG-3' corresponding to Escherichia coli 16S rDNA positions 8-27, and 5'-GTA TTA CCG CGG CTG CTG G-3', corresponding to E. coli $16 \mathrm{~S}$ rRNA gene positions 517-535. The PCR primer 5'-TCC GTA GGT GAA CCT GCG G-3', 5'-GCT GCG TTC TTC ATC GAT GC-3' was used to amplify the internal transcribed spacer (ITS) 1 region. The standard PCR mixture $(25 \mu \mathrm{l})$ contained $0.75 \mathrm{U}$ of Taq
DNA polymerase (AmpliTaq DNA polymerase, LD; Applied Biosystems, Foster City, CA), $1 \times$ reaction buffer, $2.5 \mathrm{mM}$ $\mathrm{MgCl}_{2}, 0.4 \mathrm{mM}$ (each) dNTP mix, $250 \mathrm{nM}$ (each) forward and reverse primers, and $2 \mu \mathrm{L}$ of DNA template. PCR was performed with a Gene Amp PCR system 9600 thermocycler (Applied Biosystems) under the following conditions: initial activation at $94^{\circ} \mathrm{C}$ for 3 minutes; 35 cycles at $94^{\circ} \mathrm{C}$ for 30 seconds, $55^{\circ} \mathrm{C}$ for 60 seconds, and $72^{\circ} \mathrm{C}$ for 30 seconds; and final extension at $72^{\circ} \mathrm{C}$ for 3 minutes. The PCR products were separated by electrophoresis in 3\% agarose gels containing $1 \times$ Tris-acetate-EDTA buffer and visualized by staining with ethidium bromide.

\section{Detection of bacterial and fungal DNA by DNA microarray}

We have previously developed a microarray assay, for identification of 76 bloodstream infection-associated pathogens (bacteria and fungi) from whole blood samples. ${ }^{7.8}$ This pathogen identification microarray is an assay for parallel identification of bacterial species and clinically relevant Candida species. ${ }^{8}$ Bacterial and fungal sequence data were obtained directly from the GenBank database. The $16 \mathrm{~S}$ rDNA PCR products from clinical isolates were sequenced using an automated sequencer (Applied Biosystems) and variable regions were aligned using ClustalW (http://www.ebi.ac.uk/ Tools/clustalw2/index. html) to identify the 500-bp sequence of $16 \mathrm{~S} \mathrm{rDNA}$ at the $5^{\prime}$ end, including variable regions (V1, V2, V3). Fungus-specific primers were targeted to the conserved sequences of $5.8 \mathrm{~S}$ and $18 \mathrm{~S}$, including the ITS1 region. The theoretical specificities of all designed primer and probe sequences were further analyzed using BLAST (NCBI). The oligonucleotide probes (50 bp), corresponding to the variable regions and PCR products that were amplified by the $27 \mathrm{f}$ primer and $\mathrm{r} 1 \mathrm{~L}$ primer, were spotted onto plastic slides using a microarray-making instrument (SPBIO; Hitachi Soft Engineering, Yokohama, Japan). The sequences of the 76 microorganism probes have been described previously. ${ }^{8}$ Each probe identifies the sequence of each of the 76 microorganisms, which include all causal clinical disease pathogens (patent no. WO2003/106676).

\section{Labeling and DNA hybridization}

The PCR products from samples were labeled with $\mathrm{Cy} 5$ primers of sequences 5'-Cy5-CTC ACC CGT-3' (Cy5 120R), 5'-Cy5-TGC CTC CCG-3' (Cy5 350R), and 5'-Cy5-TGC TGG CAC-3' (Cy5 520R). For the ITS region, the primer sequence was 5'-Cy5-GCT GCG TTC TTC ATC GAT GC-3' (Cy5 ITS2). The labeling reaction was performed in 20 cycles 
$\left(37^{\circ} \mathrm{C}\right.$ for 5 seconds and $94^{\circ} \mathrm{C}$ for 5 seconds) using a thermal cycler. Hybridization of the labeled samples to the microarray was carried out in $1 \times$ hybridization buffer composed of $40 \%$ formamide, $5 \times$ saline-sodium citrate $(\mathrm{SSC})$ buffer, and $0.2 \%$ sodium dodecyl sulfate (SDS) at $55^{\circ} \mathrm{C}$ for 1 hour. Before hybridization, $50 \mu \mathrm{L}$ of the Cy5-labeled sample was mixed with $150 \mu \mathrm{L}$ of $1.5 \times$ hybridization buffer, followed by denaturing at $96^{\circ} \mathrm{C}$ for 2 minutes and chilling on ice. Each sample was placed on the microchip and covered with a $40 \times 22 \times 0.25 \mathrm{~mm}$ plastic chamber (Invitrogen, Carlsbad, CA) to prevent evaporation of the probe during incubation. After hybridization, the slides were washed for 5 minutes with $2 \times \mathrm{SSC}$ exposed to $0.2 \% \mathrm{SDS}$ at room temperature, and then rinsed for 5 minutes with $0.2 \times \mathrm{SSC}$ exposed to $0.2 \%$ $\mathrm{SDS}$ warmed to $50^{\circ} \mathrm{C}$ in a water bath. Finally, the slides were rinsed with $0.05 \times \mathrm{SSC}$ and dried in a stream of air.

\section{Fluorescence scanning and automated data analysis}

Fluorescent images of the microarrays were obtained by scanning the slides with ScanArray 5000 (Perkin-Elmer, Boston, MA). The fluorescent signals from each spot were measured and compared using DNASIS Array software (Hitachi Software Engineering, Yokahama, Japan). A scan image is shown in Figure 1. Identification of the microorganism was made by automatic statistical recognition of a certain pattern of positive spots, as described previously.,

\section{Results}

No control sample was positive for bacteria or fungi in microscopy, culture tests, PCR, or microarray analysis. The samples from Cases 1 and 2 were positive for bacteria in PCR analysis of VF specimens, and the sample from Case 3 was positive for fungus in PCR analysis. The DNA microarray was used to detect bacterial and fungal pathogens from positive PCR specimens. Data analysis revealed increased expression levels of genes from specific microorganisms in the VF samples. DNA microarray analysis identified

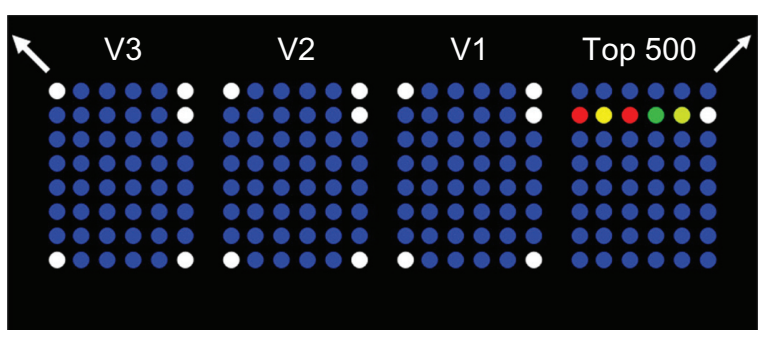

Figure I Scheme of DNA microarray. Probes of polymerase chain reaction products and each of the variable regions (VI, V2, V3) are arrayed on the plastic slide.
Klebsiella pneumonia in Case 1 (Figure 2), Streptococcus agalactiae in Case 2 (Figure 3), and Candida parapsilosis in Case 3 (Figure 4) in the PCR-positive specimens. The results of the culture tests required 3 to 4 days to obtain, and were similarly positive for K. pneumonia in Case 1, S. agalactiae in Case 2, and C. parapsilosis in Case 3. The following paragraphs provide some background on each case.

\section{Case reports}

Case 1: A 56-year-old man with a history of diabetes mellitus for 10 years had a sudden onset of high fever. He was treated with systemic piperacillin sodium (PIPC) (IV) for

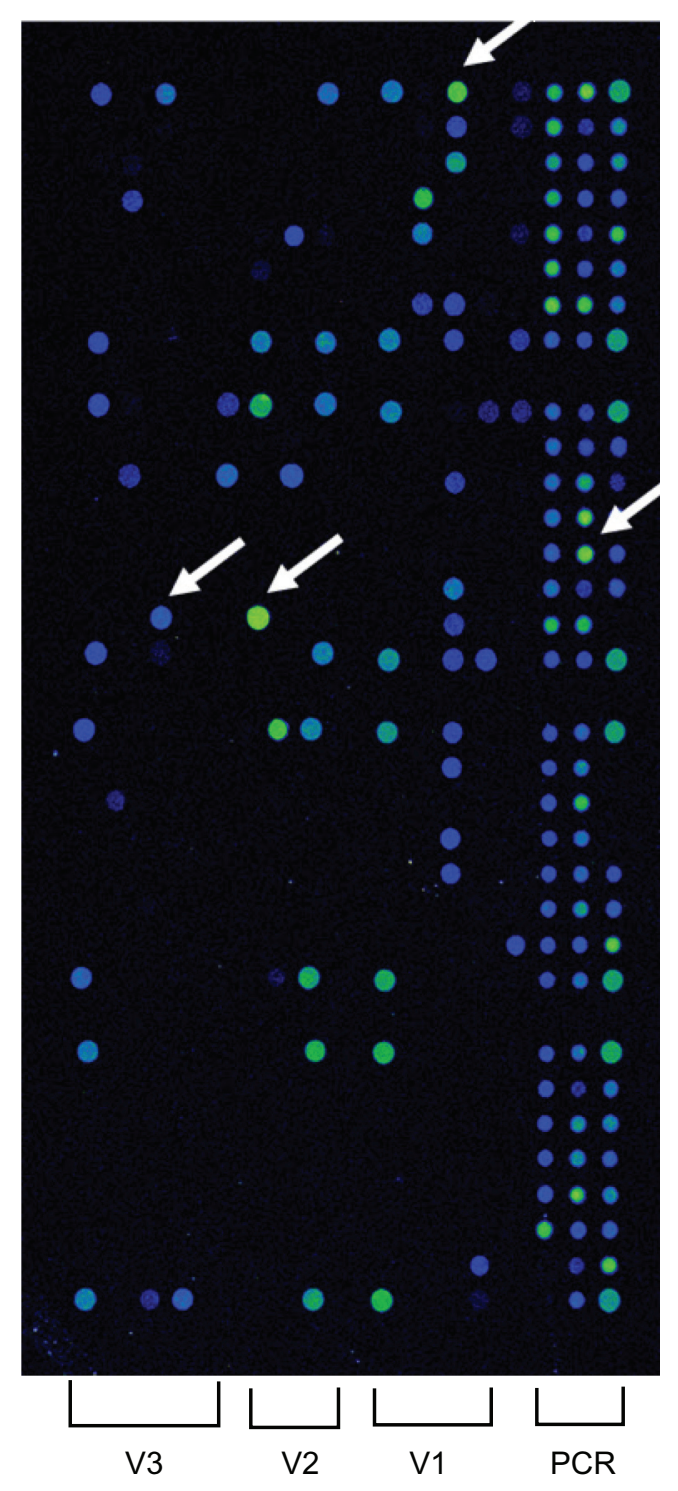

Figure 2 Results of the hybridization assay for polymerase chain reaction (PCR) amplifications from vitreous sample of case I. PCR products are spotted as a reference on the right side. Green or blue (arrow) circles in VI, V2, and V3 represent strong hybridization. Bacterial identification is determined by the combination of strong hybridization in $\mathrm{V} 1, \mathrm{~V} 2$, and $\mathrm{V} 3$. This case shows a pattern of Klebsiella pneumonia. 


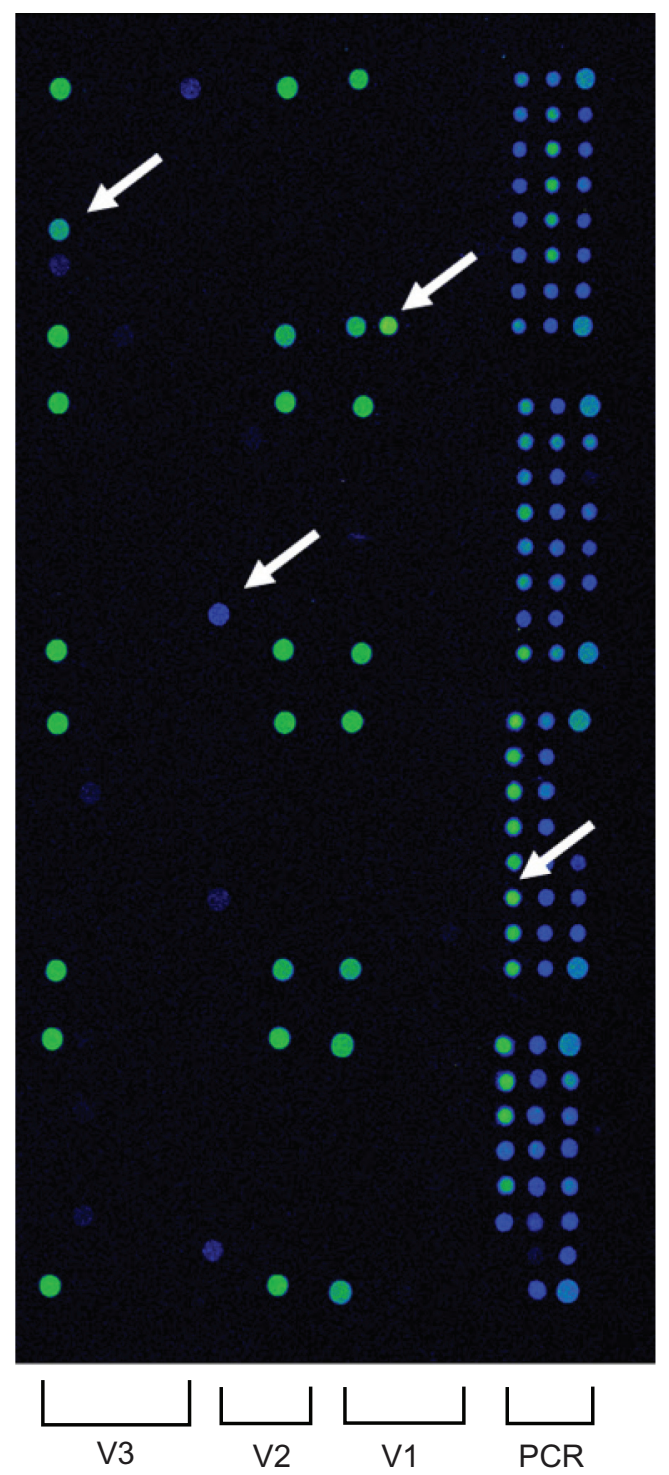

Figure 3 Results of the hybridization assay for polymerase chain reaction (PCR) amplifications from vitreous sample of case 2. PCR products are spotted as a reference in the right side. Green or blue (arrow) circles in VI, V2, and V3 represent strong hybridization. Bacterial identification is determined by the combination of strong hybridization in VI, V2, and V3. This case shows a pattern of Streptococcus agaractiae.

7 days. On day 7 he complained of abdominal pain and loss of vision OD, and was referred to our hospital. On examination, his vision was hand motion OD and 20/20 OS. An anterior and posterior segment examination revealed severe inflammation with hypopyon and vitreous haze, respectively. An abdominal CT scan showed a low-density mass in the liver consistent with a liver abscess. Septic and metastatic endophthalmitis were diagnosed and the patient was treated with meropenem + gentamicin. Seven days after his initial visit, vitrectomy was performed and vitreous samples were collected for culture tests and PCR analysis. Immediate PCR was positive for bacteria, with subsequent identification of

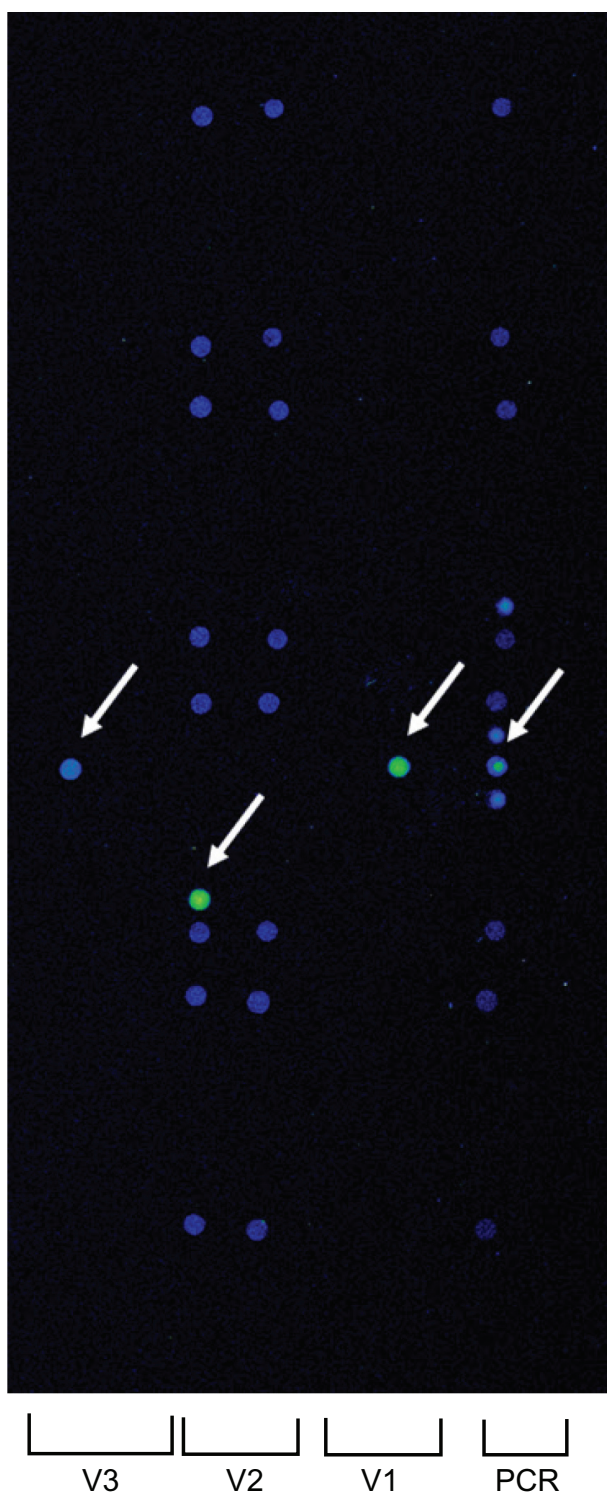

Figure 4 Results of the hybridization assay for polymerase chain reaction (PCR) amplifications from vitreous sample of case 2. PCR products are spotted as a reference in the right side. Green or blue (arrow) circles in VI, V2, and V3 represent strong hybridization. Fungal identification is determined by the combination of strong hybridization in VI, V2, and V3. This case shows a pattern of Candida parapsilosis.

K. pneumoniae by DNA microarray analysis (Figure 2). Ten days after his initial visit, a vitreous culture revealed K. pneumonia. His final vision was hand motion.

Case 2: A 74-year-old man with periodontitis visited our department complaining of severe visual loss in his left eye, and was diagnosed with endophthalmitis. His vision was 20/20 OD and light perception was OS. The patient was treated with systemic PIPC (IV) and the infection focus was examined at the same time. An initial blood examination showed that he had severe diabetes. Two days after his initial visit, vitrectomy was performed and vitreous samples were collected for culture tests and PCR analysis. Immediate PCR 
was positive for bacteria, with subsequent identification of S. agalactiae (Figure 3 ) by DNA microarray analysis. Five days after his initial visit, vitreous and oral adherent smear cultures revealed the presence of $S$. agalactiae. His vision subsequently improved to 20/200.

Case 3: The patient was a 72-year old female who visited our hospital with a complaint of dull pain and photophobia in the left eye. She had undergone cataract surgery in the left eye 3 months earlier, with no complications during the surgery. Her medical history included diabetes mellitus for 20 years. On examination, corrected visual acuity was 20/20 OD and 20/200 OS. An anterior segment examination was significant for keratic precipitates and hypopyon in the left eye. Ophthalmoscopy was normal in the right eye but showed vitreous extension of chorioretinal infiltrates, associated with vitreous cells and fluff balls in the left eye. Endophthalmitis was diagnosed and systemic PIPC (IV) were initiated, although culture of aqueous humor and blood were investigated before systemic treatment. After 2 days, her vision had worsened to hand motion and a vitrectomy with biopsy was performed. Immediate PCR was positive for fungus, with subsequent identification of $C$. parapsilosis (Figure 4) by DNA microarray analysis. Seven days after her initial visit, a vitreous culture similarly revealed the presence of C. parapsilosis, although culture results of aqueous humor and blood were negative. Systemic antibiotics were stopped and antifungal therapy was initiated after confirmation by culture. Her final vision was hand motion.

\section{Discussion}

The DNA microarray that we developed for bacterial and fungal pathogens in blood samples permitted identification of these pathogens in VF samples from patients with endophthalmitis. Our prototype microarray analysis demonstrates the feasibility of identifying pathogens in $0.2 \mathrm{~mL}$ of VF without prior amplification of the target DNA. Furthermore, the results suggest that DNA microarray analysis is more rapid than conventional bacteriological methods for identifying causative pathogens in endophthalmitis. The PCR analysis in our laboratory takes approximately 48 hours to detect microorganisms. Standard clinical identification procedures require at least 3 days and can take up to 3 weeks for microorganisms that are difficult to cultivate. In contrast, the microarray protocol can be carried out within 24 hours from drawing of VF to software presentation of the results, and gel electrophoresis for PCR product confirmation and prehybridization can be carried out in parallel with the labeling reaction. Consequently, the microarray is likely to be useful in patients who require prompt diagnosis and early initiation of antibiotic therapy.

In the present study, the sensitivity and the specificity of the microarray analysis were both $100.0 \%$ in comparison with the culture results. This suggests that the microarray data are reliable for identification of microorganisms from VF in endophthalmitis. A previous study of detection of pathogens in osteoarticular infections using our microarray showed discrepancies for some samples. Although the current study did not have this problem, false positives and negatives in the microarray analysis should be considered carefully in endophthalmitis. Taq DNA polymerase in PCR is produced and purified by E. coli and genomic DNA from the sample may contaminate the target gene; however, we have shown the lack of such contamination. Sampling should also be performed carefully to obtain correct bacterial and fungal identification.

Bacterial and fungal endophthalmitis can occur in surgery (postoperative), after trauma caused by a penetrating foreign body (posttraumatic), or during metastasis from a distant infection site (endogenous). ${ }^{9}$ In postoperative cases, coagulase-negative staphylococcal isolates are the most common pathogens. Other species include Staphylococcus aureus, streptococci, and enterococci, and Gram-positive rods such as Bacillus. In post-traumatic cases, staphylococci are the most common isolates, with $B$. cereus ranked as the second most common cause. In endogenous cases, Klebsiella spp. is the most common cause of Gram-negative bacteria. Among Gram-positive endogenous endophthalmitis, Bacillus spp. and coagulase-negative staphylococci are the most common causes. Our microarray covers the clinically common microorganisms in endophthalmitis, and the results of this study suggest that the microarray analysis is a valuable molecular tool for identifying causal agents in endophthalmitis. Although three endophthalmitis cases we presented are not the usual acute postoperative endophthalmitis cases in the present study, we believe that our microarray would be useful for detecting intraocular pathogens in the usual acute postoperative endophthalmitis cases, since this pathogen identification microarray has also allowed identification of infection-associated pathogens (bacteria and fungi) from various samples. ${ }^{7,8}$

The advantages of microarray analysis include parallel identification of different microorganisms in one assay, in contrast to multiplex or broad-range PCR methods. In a previous study, Kunimoto et $\mathrm{al}^{10}$ reported that $12.5 \%$ of culture-positive cases in postoperative endophthalmitis had polymicrobial infection. The high rate reflected the inclusion 
of fungal isolates in this series. Furthermore, Anand et al ${ }^{11}$ have shown that conventional methods of microscopy and cultures are less sensitive and time consuming diagnostic tools compared with PCR in the diagnosis of fungal endophthalmitis, because of the small number of organisms in the eye and the small sample size of the intraocular specimen collected. Thus, rapid detection capability of polymicrobial infection and identification of microorganisms using the microarray is valuable in the diagnosis of endophthalmitis.

The main limitation of the study is sample size. The number of ocular specimens is too low to fully evaluate the microarray analysis. However, although the results may be preliminary, this is the first report of use of this technology in endophthalmitis. We believe that a future, large scale, study may provide useful information for clinical care. The DNA microarray has potential as a clinical tool for microbiological diagnosis in endophthalmitis, and this will allow ophthalmologists to administer appropriate antibiotic therapy in a timely fashion and to improve the outcome for vision.

\section{Disclosure}

The authors confirm that they received no financial support for this study, and have no conflicts of interest to declare.

\section{References}

1. Lohmann CP, Linde HJ, Reischl U. Improved detection of microorganisms by polymerase chain reaction in delayed endophthalmitis after cataract surgery. Ophthalmology. 2000;107:1047-1052.

2. Anand AR, Madhavan HN, Neelam V, Lily TK. Use of polymerase chain reaction in the diagnosis of fungal endophthalmitis. Ophthalmology. 2001;108:326-330.
3. Varghese B, Rodrigues C, Deshmukh M, Natarajan S, Kamdar P, Mehta A. Broad-range bacterial and fungal DNA amplification on vitreous humor from suspected endophthalmitis patients. Mol Diag Ther. 2006;10:319-326.

4. Alizadeh A, Eisen MB, Davis RE, et al. Distinct types of diffuse large B-cell lymphoma identified by gene expression profiling. Nature. 2000;403:503-511.

5. Grant EP, Pickard MD, Briskin MJ, Gutierrez-Ramos JC. Gene expression profiles: creating new perspectives in arthritis research. Arthritis Rheum. 2002;46:874-884.

6. Cleven BEE, Palka-santini M, Gielen J, et al. Identification and characterization of bacterial pathogens causing bloodstream infections by DNA microarray. J Clin Microbiol. 2006;44:2389-2397.

7. Muto I, Hashida J, Sugimoto T, Naruse K, Tamura M, Shimadzu M. Rapid identification of sepsis related microorganisms using DNA microarray. [Article in Japanese] Rinsho Biseibutsu Jinsoku Shindan Kenkyukai Shi. 2003;14:39-43.

8. Uchida K, Yayama T, Kokubo Y, et al. Direct detection of pathogens in osteoarticular infections by polymerase chain reaction amplification and microarray hybridization. J Orthop Sci. 2009;14:471-483.

9. Callegan MC, Gilmore MS, Gregory M, et al. Bacterial endophthalmitis: therapeutic challenges and host-pathogen interactions. Prog Retin Eye Res. 2007;26:189-203.

10. Kunimoto DY, Das T, Sharma S, et al. Microbiologic spectrum and susceptibility of isolates: part 1. Postoperative endophthalmitis. Endophthalmitis Research Group. Am J Ophthalmol. 1999;128:240-242.

11. Anand AR, Madhavan HN, Neelam V, Lily TK. Use of polymerase chain reaction in the diagnosis of fungal endophthalmitis. Ophthalmology. 2001;108:326-330.
Clinical Ophthalmology

\section{Publish your work in this journal}

Clinical Ophthalmology is an international, peer-reviewed journal covering all subspecialties within ophthalmology. Key topics include: Optometry; Visual science; Pharmacology and drug therapy in eye diseases; Basic Sciences; Primary and Secondary eye care; Patient Safety and Quality of Care Improvements. This journal is indexed on Submit your manuscript here: http://www.dovepress.com/clinical-ophthalmology-journal

\section{Dovepress}

PubMed Central and CAS, and is the official journal of The Society of Clinical Ophthalmology (SCO). The manuscript management system is completely online and includes a very quick and fair peer-review system, which is all easy to use. Visit http://www.dovepress.com/ testimonials.php to read real quotes from published authors. 